vent of erysipelas may be welcomed as an encouragement to the hope of escape from mischief which is far worse.

There can be no doubt, from clinical observation and actual experiment, that the blood may thus be poisoned by matter of various kinds. And although these various substances belong to the same class-being organic, are formed probably in the same way, are alike in their larger characters, and are capable, when they gain entrance into the blood, of exciting disease of the same nature, called blood-poisoning; yet these several substances possess, within their larger characters, certain individual peculiarities which are revealed in the extent and kind of changes they provoke ; in the degree to which the blood itself is obviously affected ; in the form of local mischief which ensues, even in some measure to the particular organs which are thus more prominently involved ; and, lastly, though not least, in the proportion of the local mischief to the constitutional infection.

\section{ON SICK-HEADACHE.}

BY P. W. LATHAM, M.D., F.R.C.P.,

Deputy for the Downing Professor of Medicine, Cambridge University ; formerly $\Lambda$ ssistant Physician to the Westminster Hospital.

IN an article on Migraine, in the November number of the Practitioner, Dr. Anstie "desires to make at once the claim of independent observation," as "more than one authority has lately put forward, as if it were a novelty, the doctrine, that sick-headache is essentially a neurosis." He adds that, for several years back, he has recognised "the nervous origin of sick-headache," and that it " is certainly a neuralgia, in the majority of cases affecting the first division of the fifth."

I wish to make one or two remarks on these quotations, having lately put forward in this JOURNAL (March 23 and 30, 1872) certain views respecting the pathology and treatment of this disorder, based upon the supposition that it was a nervous disorder, but, in my opinion, certainly not what is usually termed a neuralgia.

Every one, I am sure, will concede to Dr. Anstie his "claim to independent observation ;" but, in so doing, it must be allowed that he has been somewhat remiss in his historical research. The idea that migraine is a neuralgia originated, not within the last ten years, but nearly a century ago, when Tissot in his Traité des Nerfs et de leurs Maladies (Paris, 1783 , t. iii, part. ii, p. I21) localised the malady in the same part as Dr. Anstie now does - in the first division of the fifth nerve. Romberg (Lehrbuch der Nervenkrankheiten des Menschen) calls it Neuralgia Cerebralis ; and says "We are not likely to confound this affection now-a-days with facial neuralgia as older authors, Wepfer and Tissot, have done." (Romberg on Diseases of the Nervous System, translated by Dr. Sieveking, for the Sydenham Society. London: 1853. Vol. i, p. I77.) In referring to this, Hasse remarks "It might, with equal propriety, be regarded as having its seat in the ramifications of the trigeminus (Virchow's Handbuch der Specicllen Pathol. u. Therap. I 855 . B. 4 , ab. i, p. 70 ), and adds that a satisfactory explanation is still wanting. Dr. Anstie's meaning may perhaps be, that he is the first to prove that the disorder is certainly a neuralgia ; this, I am inclined to think, has still to be accomplished. Lebert (Handbuch der Praktischen Medicin. Vierte Aufl. Tübingen. B. ii, s. 672); although he defines migraine as "a painful neuralgia probably in the ramus ophthalmicus," yet, when discussing the diagnosis of neuralgia of the trigeminus says, "Migraine has a great resemblance to neuralgia of the ramus ophthalmicus, and may really be so; but the former causes much greater disturbance of the sensorium, it spreads much more generally over the head, and is not unfrequently accompanied with nausea and vomiting; after the attack there may be an intermission for weeks or months, and the attack itself runs a more uniform or continuous course" (loc. cit., s. 699). These symptoms are not incompatible, however, with the disorder being, as I described it, an affection of the sympathetic ganglia. The theory which I advanced in my lecture (loc. cit., p. 306) was this : if by fatigue, anxiety, or other depressing cause, the general tone of the body be lowered, and with it the regulating power of the cerebro-spinal over the sympathetic system impaired, then excitement of one or more portions of the latter takes place, causing contraction of the blood-vessels under the influence of the affected portions; this excitement is followed by exhaustion or paralysis of the sympathetic, and is associated (just as it would be after section of the nerve) with dilatation of the vessels, and-if the cervical portion of the sympathetic were affected-with headache. When this lecture was written, I was unaware that any author had previously given such a marked prominence to the sympathetic in the production of the series of symptoms. I have since seen two very important papers, though containing views diametrically opposed to each other, one published in
1860, by Du Bois Reymond (Archiv. fïr Anatom. Physiol. u. Wis. sensch. Medicin. 1860 . S. 46I), the other, in I\$67, by Dr. Möllendorff (Virchow's Aritio. B. xli, s. 385). I can, therefore, lay no claim to novelty in regarding migraine as an affection of the sympathetic. Dr. Edward Liveing, whose paper in the British MediCaL Journat (April 6, 1872) leads one to look with impatient hope for the early publication of his forthcoming work, though not denying "that disorders of local circulation occur in the course of megrim, and that the implication of the sympathetic may play an important part in their production, yet regards them among the least constant and regular of the phenomena, and certainly not as essential and as the cause of the rest." Dr. Liveing regards the phenomena as those of "a nerve-storm traversing more or less of the sensory tract from the optic thalami to the ganglia of the vagus, or else radiating in the same tract from a focus in the neighbourhood of the quadrigeminal bodies." These views, I trust, we shall soon be able to discuss, when Dr. Liveing's treatise is published. He refers, however, in his paper, to Du Bois Reymond's views, but only to dissent from them ; and herein I agree with . Dr. Liveing. Du Bois Reymond assumes that migraine is a "tetanic condition of the muscular fibres of the arteries in the affected side of the head, or a tetanus of the cervical portion of the sympathetic nerve of that side" (loc. cit. p. 464); that, during the headache, the arteries are in this tetanised condition, the pupil of the affected side dilated, and the temporal artery like a hard cord. Dr. Liveing says, "I carefully compared the temporal arteries in a well-marked hemicranial paroxysm, but could discover no such increased rigidity of the one on the painful side as Du Bois Reymond describes." Du Bois Reymond himself saw a difficulty about his hypothesis, for he says, p. 465,"One symptom among those presented above, and which is never wanting in the description of migraine, certainly does not accord with our theory ; namely, the reddening of the conjunctiva, which occurs during the attack. The reason of this, probably, may be that the muscular fibres of the vessels of the conjunctiva are either relaxed earlier, or began to contract sooner than those of the other affected vessels." The tetanic state has, in fact, passed away with the commencement of the headache ; the beat of the temporal artery, instead of being hard, is soft and full, its walls have lost their tonicity and are yielding, and this condition is also shown by the reddening of the conjunctiva.

That the stage of headache is accompanied by a fulness of the vessels, is shown very strikingly by Möllendorff's investigations. Had I seen this author's paper before my own was published, I should merely have brought forward my examples in support of his views, but, at the same time, I should have insisted more strongly than he does on the antecedent contraction of the arteries, and especially its relation to the disturbance of vision which, in many cases, precedes the headache. Möllendorff says (loc. cit., p. 387), "If, during an attack of hemicrania, sufficient pressure be exerted on the common carotid of the painful side near the thyroid cartilage, as almost to stop pulsation in the temporal artery, the headache ceases as if by a charm, the eyes are joyfully opened, and the depressed and painful expression passes off. But, on discontinuing the pressure, the pain unfortunately returns with the first wave of the pulse. The first pulsations are, in fact, more painful than before; since, owing to the defective tonicity of the vessel, the fresh rush of blood causes greater vibration of its walls; the throbbing, however, soon becomes more uniform.

"If, on the other hand, before the pain has reached its climax, the carotid artery of the opposite side or the subclavian artery of the same side be compressed, the pain is then increased. The blood-stream in one direction being thus cut off, a greater volume of blood is driven towards the relaxed carotid, and, owing to the paralysed muscular tonicity, admitted into it. If, however, the pain have reached its climax, then compression of the carotid artery of the unaffected side alleviates somewhat the headache, by allowing a more rapid lateral flow of blood to the unaffected side, and so relieving the painful side. This experiment has been invariably successful with every person that $I$ have had an opportunity of seeing, during an attack of hemicrania.

"That there is an increased arterial flow of blood, resulting from the enlargement of the vessels, is also strikingly shown by the ophthalmoscope. It is, however, difficult to prevail upon the patients, during the attack, to submit to this very painful investigation. I can, therefore, only furnish the following result of repeated observation on the same individuai.

"The eyes were quite normal and darkly pigmented. During the intervals between the attacks, no difference was observable in the two eyes on examining them with the ophthalmoscope. The fundus appeared dark brownish-red; the optic papilla normal; the arteria and vena centralis retinæ in each eye equal. During the attacks, the fundus of the affected eye was bright scarlet red; the optic papilla reddened and swollen; the arteria and vena centralis retinæ broader-the latter 
nodulaterl and very tortuous, and of much darker colour than usual. The other eye had its dark brownish-red background, and its arteria and vena centralis as usual. The arterial fluxion is consequently manifest, both by the direct dilatation of the central vessels, as well as more particularly by the change in the colour of the choroid; the dilated bright red arteries concealing the pigment, and the fundus, instead of having a dark red-brown colour, appears of a scarlet colour. The thick, nodulated, tortuous vena centralis retinæ, at the same time, indicates that there is an impediment to the return of blood to the brain. Considerable injection of the conjunctival vessels is often observed extending to the circumference of the cornea. This, however, disappears as the attack passes off. The most distinct ophthalmoscopic appearances are seen in the most severe attacks."

Dr. Möllendorff also refers to the very copious secretion of limpid urine which takes place during the headache, and to the secretion of sticky unpalatable saliva; the former corresponding with what results after section of the splanchnic nerves, and the latter after section of the nerves belonging to the glands.

In my previous paper, I remarked that some of the symptoms seemed to indicate a relationship, though fortunately a distant one, between this disorder and epilepsy. The recent communication of M. BrownSéquard to the Sociéte de Biologie has an important bearing on this point. Some years ago, M. Brown-Séquard discovered that epilepsy could be developed in the guinea-pig in three or four weeks after section of the sciatic nerve near its origin, or, still more certainly, by forcible ablation of the nerve, and that then, by gently irritating a certain zone in the temporal region, fits could at any time be produced. But he found that section of the spinal cord immediately above the organ of the sciatic nerve does not give rise to epilepsy ; and this led him to suspect that the symptoms were due, not to section of the fibres of the sciatic nerve proper, but to section of the fibres of the sympathetic united to the sciatic after its emergence from the spinal cord. "Division of the great sympathetic in the abdomen produces only transient effects-incipient symptoms, as it were, of epileptic attacks, but nothing positive or definite. On the other hand, section of the roots of the last dorsal and first lumbar nerves produces epileptic attacks, and it is known that these roots furnish sympathetic filaments to the sciatic nerves. From all this $M$. Brown-Séquard concludes that it is to the section of the sympathetic that we must essentially attribute the artifical production of epilepsy." (Lancet, Oct. 5, I872, p. 502).

Would not these experiments of M. Brown-Séquard rather show that a series of morbid phenomena originating in section of the sympathetic alone might develope such symptoms as are associated with migraine? but, that for the production of epilepsy, there must be a series of morbid phenomena both in the sympathetic and in the cerebro-spinal systemstructures must be operated upon containing the two kinds of fibres ; and possibly this is the reason why, though the two disorders may be essentially different and distinct from each other, they have some symp. toms in common.

\section{ON THE MORBID EFFECTS OF ALCOHOL.}

By W. H. DICKINSON, M.D.Cantab., F.R.C.P., Senior Assistant-Physician and Lecturer on Pathology, St. George's Hospital ;
Physician to the Hospital for Sick Children, etc.

As the last number of the JOURNAL contains no further communications upon this subject, I would ask for the insertion of the few concluding remarks which appear to be required of me. As regards pothouse pathology, my opponents have in one respect answered each other-one suspecting that in the liquor trade and out of it the consumption of alcohol is about equal ; another, that persons engaged in this commerce drink so much and so fast that their kidneys are saved by the intervention of the more rapid forms of alcoholic poisoning.

Referring to Dr. Roberts's last contribution in the JoURNAL, I may repeat that my views are not based upon the registrars' reports, but merely corroborated by them. These returns, for reasuns I have shown, probably contain a larger substratum of fact with regard to renal than to hepatic disease, but are probably in all cases far removed from absolute truth. I am, indeed, surprised that Dr. Roberts, entertaining as he justly does a mean opinion of their accuracy, should appeal to them for support as often as he does.

As resulting from alcoholic drinks with any practical frequency, Dr. Roberts gives up all changes except granular degeneration; and I am glad to find that our accord has become so considerable. Alcohol has a part, as I have shown, in causing this change, which is none the less real because it has been exaggerated. It causes, also, a congestive or coarse textured enlargement of the organ, which, like other renal changes, is more often found after death than suspected during life.
The question, therefore, is, not whether alcohol ever causes renal disease, but how often, as compared with other causes. Dr. Roberts, after failing to find obvious and tangible causes for chronic albuminuria, is led often to refer it to excess in drink, though the excess has been by no means great. But reasoning by exclusion is in this instance especially liable to error. Climate, age, and hereditary predisposition tell. "The young disease that must subdue at length" is often renal. The fibrosis of age, possibly directed by atmospheric influences, appears in this latitude to run its course faster in the kidney than in other organs. Granular degeneration less often arises from causes which can be distinctly isolated than in double association with bodily decay and with the ever acting surroundings which scarcely suggest themselves as causes of disease. Hence we must not reckon too much on the absence of the more glaring causes of renal disorder, nor be hastily driven to assign it to slight alcoholic excess. As we cannot expect to expose the origin of this disease save in a minority of instances, the absence of a "definite causal antecedent" goes but a little way towards establishing its descent from alcohol.

Touching the effects of alcohol, as gathered from the morbid anatomy of traders in liquor, Dr. Roberts thinks that these persons display only the acute, not the chronic, results. He thinks that renal disease results especially from small long continued excess, while the persons in question display the results of great or drunken excess. Much caution, however, is necessary in ascribing renal disease to such excess as requires a considerable proportion of life to produce its operation, since it is difficult to say how much may be due to time and climate, which thus have room to intrude. Besides this, I think it is clear that the observations in question do not only or chiefly refer to drunken or rapidly poisonous excess : they display the results of many rates of drinking, and give scope and verge enough for all its consequences. Of these, the chronic are the more prominent. It is probable that, with those who follow liquorous pursuits, soaking prevails rather than revelry. They are business-like rather than festive; and, as a rule, poison themselves, not with celerity but with perseverance.

I have given the average age of the alcoholic traders as 36.8 years; of the contrasted persons following non-alcoholic pursuits, as 40.6 . Cieteris paribus, we might expect a slightly greater proportion of the granular kidney in the class having the longer average of life; but the difference between them (under four years) is not such as to make comparison very unfair on the score of age. Some further particulars may be of interest. The traders in liquor died at ages varying from 16 to 73 ; the contrasted class at ages varying from 16 to 87 . The following table shows how many of each class died in each decade.

\begin{tabular}{|c|c|c|c|c|c|c|c|}
\hline Age at Death. & \multicolumn{4}{|c|}{$\begin{array}{c}\text { Alcoholic Traders. } \\
\text { I } 46 \text { cases. }\end{array}$} & \multicolumn{3}{|c|}{$\begin{array}{c}\text { Non-Alcoholic Traders } \\
\text { I } 49 \text { cases. }\end{array}$} \\
\hline From I 6 to $20 \ldots$ & $\cdots$ & $\ldots$ & IO & $\cdots$ & $\cdots$ & $\ldots$ & I I \\
\hline From 21 to $30 \ldots$ & $\cdots$ & $\cdots$ & 37 & $\cdots$ & $\cdots$ & $\cdots$ & 39 \\
\hline From 31 to $40 \ldots$ & $\cdots$ & $\cdots$ & 50 & $\cdots$ & $\cdots$ & $\cdots$ & 28 \\
\hline From 4 I to $50 \ldots$ & $\cdots$ & $\cdots$ & $3 I$ & $\cdots$ & $\cdots$ & $\cdots$ & 32 \\
\hline From $5 \mathrm{I}$ to $60 \ldots$ & $\cdots$ & $\cdots$ & 12 & $\cdots$ & $\cdots$ & $\cdots$ & $2 \mathrm{I}$ \\
\hline From 61 to $70 \ldots$ & $\cdots$ & $\cdots$ & 5 & $\cdots$ & $\cdots$ & $\cdots$ & I3 \\
\hline From 71 to $80 . .$. & $\cdots$ & $\cdots$ & $\mathbf{I}$ & $\cdots$ & $\cdots$ & $\cdots$ & 4 \\
\hline From 81 to $90 \ldots$ & & $\ldots$ & 0 & $\cdots$ & & & I \\
\hline
\end{tabular}

The mortality from alcohol between the ages of 31 and 40 is striking, and it may be worth while to inquire into its causes. The following table gives the leading causes of death within this decade, as observed in the two classes.

$$
\text { Chief cause of Diath at Ages from } 3 \mathrm{I} \text { to } 40 .
$$

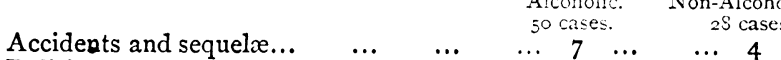

$\begin{array}{lllllllll}\text { Delirium tremens } & \ldots & \ldots & \ldots & \ldots & 7 & \ldots & \ldots & 4 \\ & \ldots & \ldots & \ldots & 7 & \ldots & \ldots & \circ\end{array}$

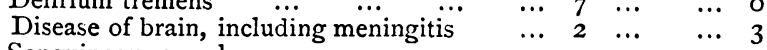

\begin{tabular}{lccccccc} 
Sanguineous apoplexy $\ldots$ & $\ldots$ & $\ldots$ & $\ldots$ & 2 & $\ldots$ & $\ldots$ & 3 \\
\hline
\end{tabular}

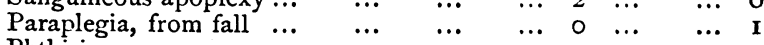

$\begin{array}{lccccccccc}\text { Phthisis } \ldots & \ldots & \ldots & \ldots & \ldots & \ldots & 0 & \ldots & \ldots & 1 \\ \text { Pneumonia } & \cdots & \cdots & & \ldots & \ldots & \text { 12 } & \ldots & \ldots & 7\end{array}$

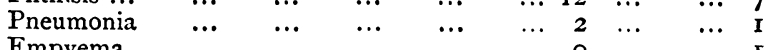

$\begin{array}{llllllllll}\text { Empyema } & \ldots & \ldots & \ldots & \ldots & \ldots & 0 & \ldots & \ldots & \text { I }\end{array}$

$\begin{array}{lllllllll}\text { Bronchitis } \quad \ldots & \ldots & \ldots & \ldots & \ldots & \text { I } & \ldots & \ldots & \text { I } \\ \text { Disease of heart } & \ldots & \ldots & \ldots & \ldots & 3 & \ldots & \ldots & \text { I }\end{array}$

$\begin{array}{lllllllll}\text { Aneurism } & \cdots & \cdots & \cdots & \cdots & 3 & \cdots & \cdots & 3\end{array}$

$\begin{array}{lllllllll}\text { Disease of liver } \ldots & \ldots & \ldots & \ldots & \ldots & 0 & \ldots & \ldots & \text { I }\end{array}$

$\begin{array}{llllllll}\text { Albuminuric disease of kidney } & \ldots & \ldots & 3 & \ldots & \ldots & 0 \\ \end{array}$

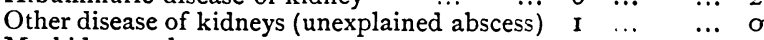

$\begin{array}{llllllllll}\text { Morbid growths } & \ldots & \ldots & \ldots & \ldots & 2 & \ldots & \ldots & \text { I }\end{array}$

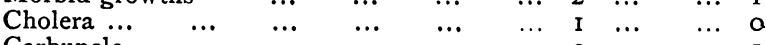

$\begin{array}{llllllllll}\text { Carbuncle } & \ldots & \ldots & \ldots & \ldots & \ldots & \text { 1 } & \ldots & \ldots & 0 \\ & \ldots & \ldots & \ldots & \ldots & \ldots & \circ & \ldots & \ldots & \text { I }\end{array}$

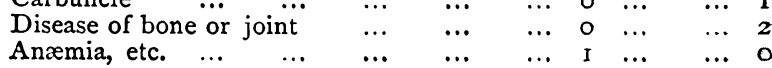

